experiments of Neuschlosi, ${ }^{40}$ who found that an emulsion of lecithin in water possesses a surface tension dependent on the amount of $\mathrm{Ca}$ present. Too much or too little Ca had the same effect. In the therapeutic application of lime salts one also often notices opposite effects according to the amount used.

To return for a moment to what Prof. Bayliss has called the "Clowes's effect," it would seem that the view of the American author is strongly supported by our experiments on the stereo-isomeric sugars. We have seen that pores are left between the oildrops, and it is obvious that these pores, because they are subjected to the surface tension at the boundary, assume varying shapes. Now pores of a definite shape could allow sugars of a definite configuration-e.g., lavulose - to pass through, while holding back sugars -e.g., glucose-of another configuration. One might be inclined to explain this phenomenon by the aid of differences in viscosity or surface tension. But we have found with Miss S. C. Hamburger that these physical constants are the same for levulose and for glucose. How can one explain this separation of glucose from lævalose, therefore, other than by supposing that the shape of the ultra-microscopic pores in the sieve plays a decisive part? Our experiments thus lend support to Clowes's theory, and vice versa the mechanism of specific permeability has become clearer.

Finally, it may be said that the conditions shown in our sketch by the portion below the line do not, as a rule, occur in physiological circumstances. In fact we know that, as a rule, all the cells of the body are permeable to water. But there are exceptions. When blood is diluted with a great deal of water most of the red corpuscles in absorbing water loose their colouring matter and the mixture has become transparent. But after centrifugalising I often saw a deposit which examined by the microscope proved to consist of red corpuscles. These cells must have been impermeable to water. Red corpuscles treated with cobra venom are also impermeable to water, and the same is true of the eggs of sea-urchins. 11 When put in distilled water the latter does not enter the eggs, as Ralph Lillie has pointed out, but on adding some Ca-ions their impermeability to water is lost.

References.

1. Hamburger: Zeitschr. f. Biol., 1889, p. 414

2. Hamburger: Koninkl. Akad. $v$. Wetensch. te Amsterdam, meeting of Dec. $29 \mathrm{th}, 1883$.

3. Hugo de Vries: Koninkl. Akad. v. Wetensch. te Amster dam, meeting of Oct. $27 \mathrm{th}, 1882$.

. Yant Hoff: Wie die Theorie der Lösungen Entstand ichte d. Deutsch. Chem., Gesellsch., xxvi., 6, 1894.

. Arrhenius: Zeitschr. f. Physik., Chemie, i., 63, 1887.

an 27 th, and Feb. 24th, 1894

an. 27h, and Fen 1892,134 and 360

8. Overton: Studien über die Narkose, Jena, 1901 .

9. Hamburger : Zeitschr. f. Biol., Xxviii., 1892, 405 .

10. Zuntz: Dissert, Bonn, 1868 ; Loewy und Zuntz: fiüger's Arch., lviii., 1894 , p. 511 .

11. V. Korányi :
xxxiv., 1898, p. 1 .

12. Y̌andeli Henderson: Jour, of Biol, Chem, xxxiii., 333, 1918.

12. Yandeli Henderson: Jour. of Biol. Chem., xxxiii., 333, 191

14. Hamburger: : osmot. Druck u. Ionenlehre, Bd. iii., p. 53.

15. Hamburger : Osmot. Druck u. Ionenlehre, Bd. iii., p. 53. 1906

16. Hamburger : Wiener Klin. Wochenschr.,

17 ; de Boer : Jour. of Physiol., li., 211, 1917.

17. Ham 1910 .

18. Koeppe: Pfluger's Arch., lxvii., 189, 1897.

19. Hamburger : Zeitschr. f. Biol., 1891, p. 405

20. Girard: C. r. de l'Acad. d. Sciences, cxlviii., p. 1047, 1909 ; clxx., p. 821,1920

21. Lazarus Barlow: Jour. of Physiol., xix., 140, 1895.

22. Gryns: Koninkl. Akad. v. Wetensch. te Amsterdam,

23. Nagel's H. 24th, 1894; Pflüger's Arch.

24. Hamburger: Physik., p. 74 ; 1907 .

zyten, Wiesbaden, 1912 .

25. Snapper : Biochem. Zeitschr., li., p. 62, 1913

26. Hamburgel: Arch. (f. Anat. u.) Physiol. i., p. 317, 1898. 27. Hamburger and Brinkman: Proceedings of the Kononkl.

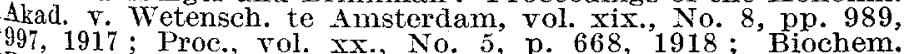
Zeitschr. ixxxviii., p. 97.1918 : Proc. vol, xxi. No 4, 548 , 1918; Biochem. Zeitschr., xciv., p. 131, 1919; Hamburger: (Continued at foot of next column.)

\section{CRANIOTABES OF THE FOETUS AND INFANT.}

\section{By EDMUND HUGHES, M.R.C.S., L.R.C.P. LOND}

IN a previous paper ${ }^{1}$ I recorded some rosults of a clinical inquiry into this subject. The account then given was composed under the combined disadvantages of military service and paper shortage ; and this was unfortunate, because the contentious nature of certain of the findings called for their rather full presentment. I shall therefore make no apology for re-stating these findings in somewhat more adequate form.

Broadly, the position then reached was that the recognised "craniotabes" arising during the first few months of infancy is in many, and probably in most, cases only a fresh manifestation of a state of craniatrophy already existing in later foetal life, This fotal cranjatrophy, having no physical differences from the later form, and occurring predominantly in the same individuals, was therefore held to deserve the same title. Verification of this finding would entail a re-scrutiny of the common belief that craniotabes is a sign of rickets. A simpler solution of the difficulty would be to infer the causality of syphilis. But the only definite contribution to the problem of causality I was able to make consisted of some fresh evidence tending to rule out syphilis as an acting or proximate cause. The evidence given was, I think, sufficient for that purpose; and it must be remembered that observation alone, though powerless to decide what is causal, can often determine what is not.

I will now go over the previous findings, incorporating such fresh material as has since been obtained. The total case-material is 154 .

\section{Immaturity of the Skull.}

In connexion with yielding areas in the skull at birth, the problem was early raised in course of this inquiry as to what characters of this kind in the newborn skull can be legitimately ascribed to immaturity. To determine this point, a parallel study was made on some hundreds of living neo-natal crania at various stages of development, and of stillborn and non-viable crania, in situ and detached.* Seeing that in all $\mathrm{my}$ cases of foetal craniotabes the parietal bones were attacked, and that all were born at or near term, interest here centres on the condition of the parietal at and near the end of the foetal period. The result of study makes it clear that the condition I call fotal craniotabes and the condition of the parietal due to immaturity are entirely distinct. In the first there is discontinuity of the bone-forming spicules - a true atrophy in some part of their course-

* For the great majority (about 130) of these latter my thanks are due to Prof. J. M. Beattie, who kindly placed at my disposal The stillborn material brought to the Liverpool City Laborato
This mat has also furnished several morbid specimens.

(Continued from opposite column).

Brit. Med. Jour., March 8th, 1919 ; Proc., vol. xxii., No. 4. pp. 351 and 360,1919 ; Hamburger and Alons: Biochem, Exp. Physiol., xii., p. 2, 1919

28. Bahlmann:' Dissert, Utrecht, 1920

29. Rona u. Takahashi : Biochem. Zeitsehr., xlix., 370, 1913.

30. Sörensen : See Neuberg, Der Harn II., p. 1396, 1911.

31. Brinkman : Biochem. Zeitschr., xcv., p. 101, 1919

32. Brinkman and $V$. Creveld: Yet to appear.

33. Brinkman and V. Dam : Koninkl. Acad. $v$. Wetensch. te Amsterdam, meeting of Dec. 18th, 1920 .

34. Not yet published.

35. V. Creveld and Brinkman : Koninkl. Acad. v. Wetensch. te Amsterdam, meeting of Dec. 18th, 1920.

36. Brinkman and V. Dam: Arch. Internat. de Physiol., xv., p. 105,1919 .

1919 .

38. Clowes: Jour. of Physic. Chem., xx., p. 407.

39. Bancroft : Jour. of Physic. Chem., Xvii., p. 501

40. Neuschlosz: Pflüger's Arch., clxxxi., 17, 1920.

41. Lillie: Amer. Jour. of Physiol., $x ., p .419,1904$; xvil., 89, 1906; Xxi., 200, 1908; xxiv. 459, 1909; Xxvii., 289, 1911 . Full particulars about permeability until 1901 in Hamburger : Osmotischer Druek u. Ionenlehre, 1901-04 (Bergmann, Wiesbaden). 
together, sometimes, with attempts at repair; in the second, merely an evenly progressive ossifying process in an incomplete stage. Moreover-and this was my main object-mistakes can seldom arise in palpating these bones. The normal parietal at the period in question is rigid, and the only spot where localised yielding due to immaturity is liable to occur is a small symmetrical area about the parietal foramina. "These foramina, or the "sagittal foramen" replacing them, lie about 1 to $1_{4}^{1}$ inches from the posterior fontanelle. The sense of weakness at this point is due to irregular spacing of the spiculæe near the margin. Except for this, which is easily excluded, the parietal at about term presents no feature due to absolute immaturity which could simulate craniotabes. Yielding of large portions of the periphery like that normal at the seventh month, and due to relative immaturity, is rare enough to be a curiosity, and in any case could not well be mistaken for anything else. In examining many of these bones, a degree of weakness sufficient to cause doubt is occasionally met with along the anterior half of the inner margin. This I at first thought to mean immaturity also, but the $X$ ray reveals an early stage of diffuse atrophy. Such cases, in fact, occupy an intermediate position towards clinically obvious craniotabes, but need not be taken stock of in compiling morbid series.

There is thus no practical source of fallacy in diagnosing craniotabes in the newborn by clinical means.

\section{Craniotabes in the Fotus.}

I shall throughout use the term craniotabes to denote a craniatrophy which has reached a clinically recognisable degree, and which is dis- fortal with the infantile form, and this will now be considered soriatim.

\section{I'hysical Characters.}

The atrophy occurs as depressions found on the inner aspect of the bone. The atrophic areas show both lacunar and diffuse formations, both being frequently present in the same bone. The lacunar areas occur as membranous spots isolated in the bone, or it may be abutting on its margins here and there. Their edges show a thinning down of the bone to the membranous ol: semi-membranous centre, which centre varies in my specimens from about 0.5 to $2.5 \mathrm{~cm}$. in greatest width. The diffused areas may be membranous in part or wholly, or merely so far atrophied as to yield with ease. Where the bone is reduced to a thin shell, but not entirely lost, and is palpated in situ through its integuments, it is apt to feel "leathery," though still resilient; areas of total atrophy feel flaccid or "parchmenty," according to their state of tension. Any part of the parietal may be involved, but in all cases I have recorded the site of election has been the inner half, and especially its anterior two-thirds. In 76 instances (66 in vivo) the parietal was affected in all, the right alone in 27 , the left alone in 13 , both bones in 36 . In 2 the upper portion of the frontal was also involved. The squamo-temporal and squamo-occipital were not found implicated in any.

Palpation is sufficient to settle the fact of atrophy, and to determine its main features; but in detail it is inaccurate, and this must apply also to palpation of infantile craniotabes. Parts bridged by bone are apt to vield like one, and adjacent bone, especially on the peripheral side, through loss of its normal
Fig. 1.

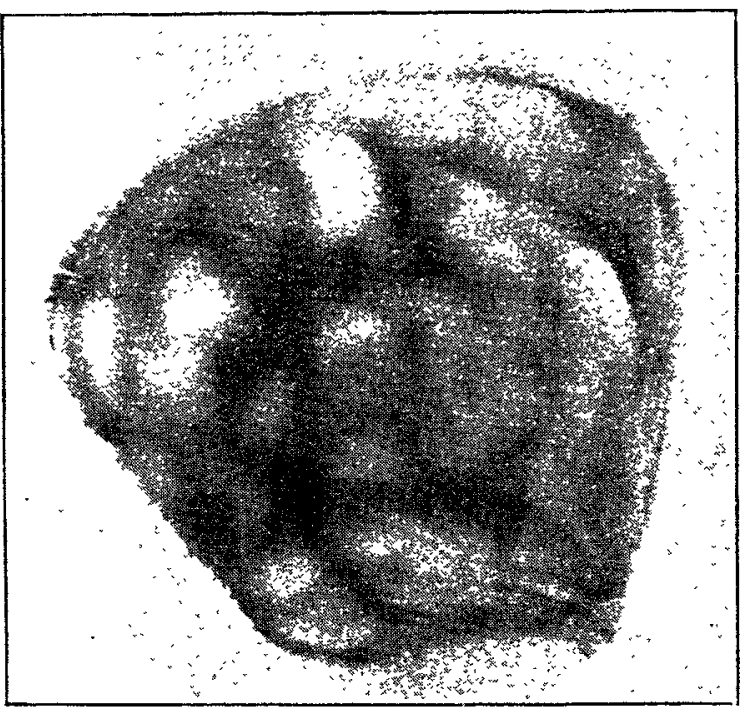

Parietal bone of subject at term with cranioanterior two-thirds of internal segment.
Fla. 2.

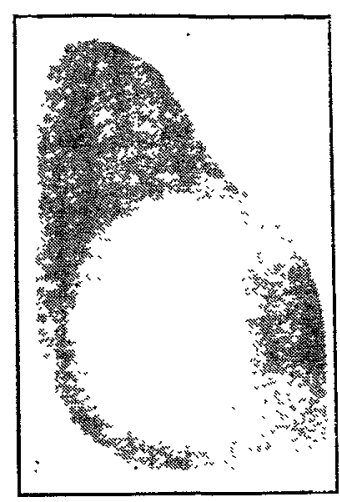

liepair proceeding in a at birth.
FIG. 3. covered by gentle palpation of the bone in situ. The term "infantile craniotabes" will be used to denote a craniotabes which first appears at some time after birth.

The prevailing opinion, as reflected in text-books, sc., is that craniotabes is a condition developing in jnfancy, and it is so described. Some have remarked on the occurrence of bony defects at birth, and ascribed them to bone-immaturity. The existence also of a condition at birth deemed to be craniotabes has been recognised by some authors, but, so far as I am aware, as a rarity. Having found this latter condition congenitally with some frequency, and cxchuded immaturity, my wish was to ascertain whether its analogy with the infantile form was anything more than a superficial resemblance. Evidence was then gradually obtained which collectively affords a sufficient proof of the identity of the

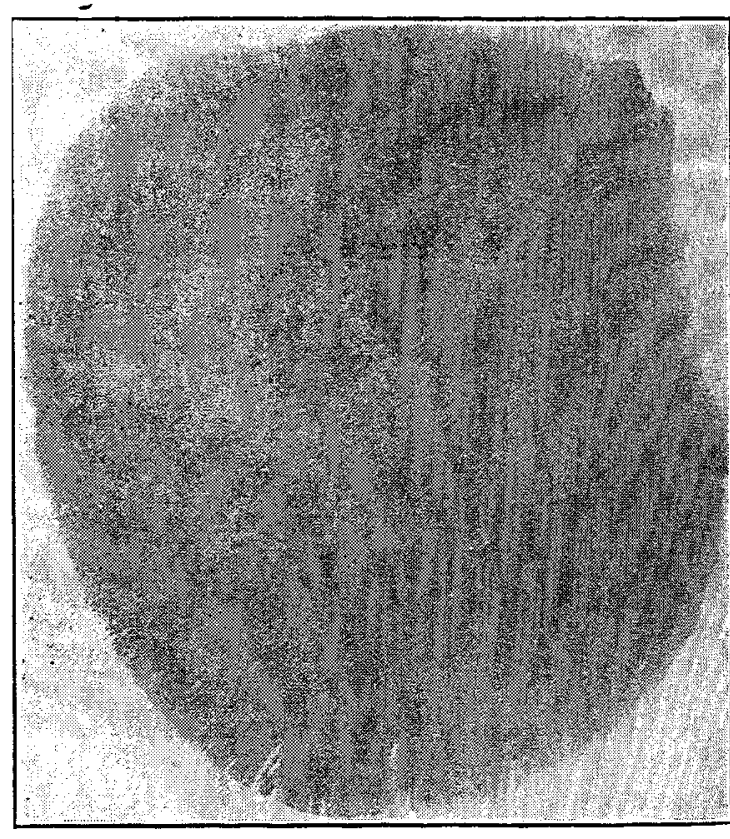

A normal parietal at term (vertex presentation?.

support, sometimes seems to belong to the atrophied area. For this reason my previous illustrations, based on results of palpation, represent very imperfectly the true state of things. The radiograph now shown is sufficiently illustrative, though the definition might perhaps be improved. (The low density of these bones entails the use of a very "soft" tube.) For comparison, a normal parietal at term is included, and one showing infantile craniotabes taken as figured from Carpenter's book on syphilis in children, and given by the author to illustrate that form.

\section{Macroscopic Details.}

In parietals at birth showing normal ossification the vascularity of the bone may appear uniformly distributed, or show a degree of irregularity in this respect. In those showing craniotabes, however, there is sometimes, not always, definite hyperæmia 
with an irregular distribution. This is best seen in more adranced examples, and after hardening, when their dark colour is in sharp contrast with the appearance of normal specimens. The hyperamia is seen to be more pronounced in a broad zone round the atrophied parts. The pericranium is not noticeably thickened. This structure is often ill-developed at birth, and may not strip very easily off a normal bone. It usually strips off an atrophied site, though the presence of old blood may cause partial adhesion and pigmentation. The same description applies to the dura, which, moreover, is thinned over membranous sites. One naturally thinks of intra-partum

FIG. 4.

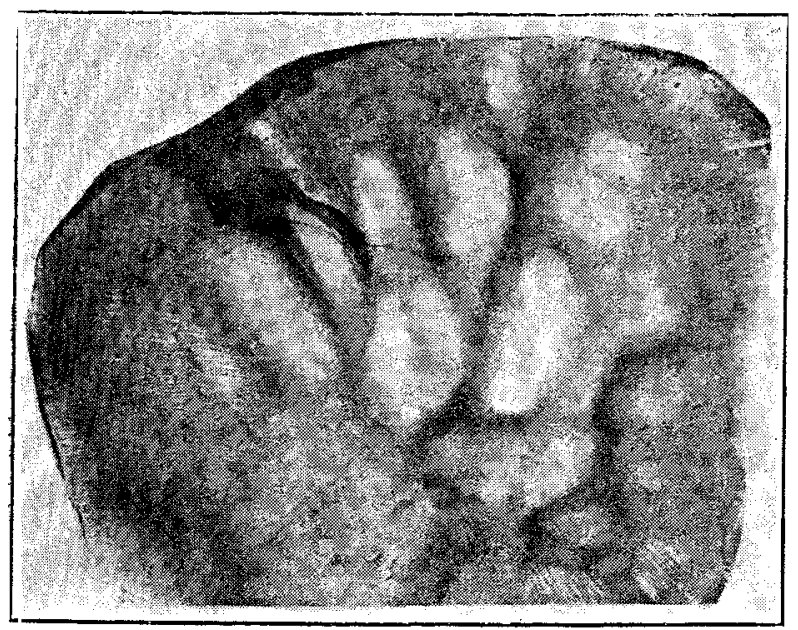

Part of parietal showing infantile craniotabes. (From Carpeuter.)

damage in these cases, but in my confinement series only one stillbirth occurred, probably from unrelated causes: the others seemed none the worse, then or afterwards. Though numbers have been re-observed at later ages, no evidence of cortical injury has been met with. The following shows, however, the intrapartum possibilities in a rather extreme case-a stillborn female infant in $\mathrm{my}$ laboratory series:-

There was much inner segment atrophy of both parietals, chiefly diffuse and partial. The left showed a fracture $1 \frac{3}{4}$ inches in length, parallel with the sagittal edge and involving the thinned bone near its junction with normal bone. The pericranium here was torn through, and a layer of recent blood extended beneath it as far as the eminence. The underlying dura, otherwise uninjured, was separated from the bone by blood and serum (commencing internal cephalhæmatoma). Further forward, both dura and pericranium were partially adherent to the atrophic bone up to the fontanelle, the adhesion being due to a thin deposit of old (ante-partum) blood. The subjacent cortex was apparently undamaged.

one would expect sub-pericranial hrematoma after the birth of severely tabetic skulls, especially where the margins were diffusely atrophied. Of 11 examined post mortem, three showed atrophies of this type, and in all three there was commencing hæmatoma. Till recently, the significance of this point had unfortunately escaped me, so that the absence of record of it among those that survived may mean a fact or an onission. Is this accident, however, probably occurs in under 1 per cent. of all births, it is unlikely to. complicate these cases with any frequency, at any rate to a clinically obvious degree. But when present, especially on both bones, the possibility of underlying craniotabes may be borne in mind. The histology of these bones will be given in a later note.

\section{Mechanical Causation.}

This is the only certain element in the causal nexus of craniotabes in general. Yet that it has sometimes been disregarded is shown in the statement of Carpenter ${ }^{2}$ that craniotabes (infantile) cannot be a sign of rickets because it is getting better while rickets is developing; and by an argument quoted from Wieland ${ }^{3}$ that the imperfectly ossitied areas occurring in the newborn do not mean craniotabes because they occupy a different part of the bone. This latter is also an error of fact, as they may be found in the same part, but the observed differences of position at the two periods is exactly what would be expected if the two conditions were identical. At both periods they occupy the most dependent regions of the skull, the regions of maximum strain. Igain, it is a mark of a true cause (in action) that when removed its effect (if impermanent) always begins to cease from that time forward. Events were followed in some fifty or more of my cases, and in all progressive repair was observed to take place where (as is usually the case) the foetal area was situated outside the new regions of pressure after birth.

The physical characters tell the same tale. In the normal majority of skulls at term, the indentations accommodating the cortex are as yet ill-marked and scanty. Craniotabes (in general) implies a morbid exaggeration of these in dependent parts. For the foetus, and in head positions, one must infer a double force of compression-tension for both inner and outer strata. The design of the parietal bone bears out this inference, at any rate for the outer stratum. There is, of course, no diploëjc space at this age. The inner layer is thin and compact: the outer layer, in contact with the inner, and about two to three times its thickness, I find to show partial interlacement of the radiate fibres, together with a general tendency to slant from the inner towards the outer surface from centre towards periphery. This latter arrangement, so far as it exists, would tend to equalise strains from external pressure, and to transfer them towards the stronger interior bone. Owing to the general structure, external compression strain would tend to be transferred to the apex of a wedge of strain whose base is on or faces the margin, and this, so far as there is need to assume it, would help to explain the frequent occurrence of atrophic holes in the interior. Internal compression by the semi-diffiuent brain-mass of the foetus should be moderately uniform, but with a gravitational stress concentrated on the inner segment. The greater tendency to diffused and other atrophy in this segment is, no doubt, thus accounted for. One can only postulate the main features of so irregular a mechanical system as this, whose complexity is increased by the various foetal movements, and by such developmental variations as may occur in the bones themselves. There is further to be included the inconstant lie of the head in relation with the uterine wall, the obliquity of the uterine axis, \&c. The greater implication of the right parietal is of interest in connexion with the lower lie of that bone so far as gravitation is concerned, in first positions; while the general anterior position of these atrophies together with other points should help in determining the normal stresses on the foetal head prior to labour. I have only found craniotabes in births by the vertex. Its occurrence in other than head presentations would indicate that the foetus had recently changed its position.

\section{Clinical Course.}

Rigidity of the fotal area remored from stress is generally accomplished, clinically speaking, by the end of five weeks, but repair may be much more gradual and prolonged to three months. The finding of areas far forward during infancy, if this is not far advanced, would mean their origin in the foetus. During the first four months of infancy fresh areas in the posterior segment are very liable to develop, and the case then becomes one of infantile craniotabes, which subsequently runs its usual course. This sequence occurred in 33 out of the 38 which I was able to follow up. Of 117 born without recogmisable craniotabes, and followed to some part of the fourth month, 10 afterwards showed it. Allowing for modification by larger figures, the discrepancy found (about 86 as against 8 per cent.) is still great enough to justify my inference that the bulk of infantile cases are recruited from those showing 
recognisable craniatrophies at birth. This is well explained for many by supposing the skull at birth already prepared for further craniotabes by a degree of atrophy in the posterior segment as yet unrecognisable to palpation, and not to be detected by any but radiographic means. It is, moreover, in this quadrant, part of the segment most prone to atrophy in foetal life, that I find infantile craniotabes to more commonly begin. It may also be observed to start from the thinned margins of small atrophic areas found in the posterior segment at birth. Such considerations may explain why most infants escape post-natal craniotabes, though subject to like conditions. But it may be also plausibly argued that the organic causes of decalcification present in the foetal state are carried on into infancy.

Enough has now been said to indicate that the inception of craniotabes as a pathological event must be relegated to foetal life, if not always, then very often. In connexion with the whole argument the absolute frequency of pre- and post-natal forms needs to be worked out. My own figures (industrial population of Liverpool) give so far for all grades of the fotal form 21.6 per cent. (60 out of 277 unselected vertex births). A series of still-births furnished ten examples in about 63 (in a few of these the presentation was uncertain). For the infantile form a recent probable estimate by Wieland ${ }^{4}$ gives about 20 per cent. of all infants, presumably studied in a city district. These figures, so far as they go, tend rather to support the thesis just advanced.

\section{Infantile Craniotabes.}

My material here is 109 cases, but any deficiency in point of numbers has been, as I venture to think, more than compensated for by the method of continuous and intensive study given to individuals. Results as to localisation agree closely with those of Carpenter, who found the occipital seldom affected in comparison with the parietal. In all my cases where the occipital was affected, there was at some time more pronounced or extensive atrophy in the parietal, and there was evidence or proof that the former was involved secondarily in point of time. The occipital, however, may be the last to heal. The statement of Stoeltzner ${ }^{5}$ that craniotabes is only found after the first three months is contradicted by my results, numbers developing during the second month. The earliest began in the fourth week, the latest at the end of the fourth month. Most, however reach a maximum by this latter age, and thereafter begin to regenerate. The mechanical conditions furnish the key to the period of incidence. Relief of pressure is brought about earlier in some than others, but in most is sufficiently accomplished by or before the end of the fifth month. Accordingly we find craniotabes disappearing after this time, given relief of pressure, whatever the child's state of health may be. Difficulty has been felt by some ${ }^{6}$ in assignin the same pathology to diffused and lacunar formations. This I do not share, since the same case may represent the lacunar form when it begins, the diffuse form at its full development, and the lacunar form again as it heals. In areas widely atrophied, remnants of partially calcified tissue are often left, and regeneration occurs from these as well as by irregular invasions of bone from the centre of ossification. The result is that a broadening trabecular arrangement of new bone is apt to be formed, enclosing ever-dwindling atrophied spaces. If the case is first seen in this last phase, it may appear sui generis, especially since manifest rickets may be present at these ages. The variations in contour of the back of the skull may be held responsible for some of the varieties in form and position met with.

\section{Organic Causation.}

The mechanical causation of this curious condition is clearly only a part of a causal nexus. Though the great majority of individuals are subject to closely similar mechanical conditions, only a minority - say one-fifth-develops craniatrophy to the clinically recognisable degree. In this minority, therefore, decalcification must bo promoted by some morbid agency. Here I shall deal with syphilis and rickets (or rather, the as yet unknown causes of rickets) † as possible morbir agencies, in the light of such data as the present inquiry can contribute. I find it possible for a child to have fotal followed by infantile craniotabes, and to pass through infancy and earlier childhood without showing any sign of either disease; but this observation has little real weight. "Rickets may be arrested before it is clinically demonstrable and syphilis may remain clinically latent. Host craniotabetics show either one or both; and by different schools of opinion the causality of both separately or combined, has been asserted. though as a rule with little serious attempt at proof. The problem is by no means an academic one, seeing the therapeutic needs of child and mother on either assumption, and the importance to the theory of rickets of a decision on the matter.

Regarding syphilis first, its relation is beyond dispute, for it is consistently present in series, includ ing my own, to as much as 50 per cent. or more These findings, moreover, are based on clinical evidence, and a positive residuum over and above this must be allowed. From historical analogies, the argument, therefore, seems a fairly strong one for the necessary antecedence of syphilis; but the connexion needs examining further. Carpenter, who devoted long attention to this subject, estimated that about 50 per cent. of congenital syphilitics show craniotabes. If the above estimate of about 20 per cent. of all infants is also near the mark, we should then be required to assume that some 40 per cent. of infants, in our city populations, are born with syphilis - an estimate very widely in excess of any yet made on other grounds, clinical or pathological.

The same observer prepared charts showing the coincidence of craniotabes with the manifest syphilis of the earlier months.? Granting the coincidence en masse, we have yet a very good mechanical reason for the predominance of craniotabes at these ages, quite apart from the activity of an accompanying syphilis; moreover, the coincidence largely disappears on going into detail. The maximum of each is generally reached at different times, and if indivi duals are studied in continuity, their craniotabes is found to have an independent career, determined by the pressure conditions. Moreover, craniotabes shows indifference to an otherwise successful course of mercury. This rule has been uniform in my experience when cases are chosen at the right time, say those starting in the second month, which nearly always will spread in natural course. It is useless to select cases at the period of natural healing, since this goes on at differing rates. It is also noteworthy that extensive cases sometimes run their whole course without any sign of syphilis. In 10 stillborn instances examined, $S$. pallida was not found in liver, spleen, and lung, and the Wassermann reaction, taken in 9 , was negative.

While such considerations, together with other points not now enumerated, all go to discredit the causal agency of syphilis, its more remote causality could not well be excluded so long as we are largely ignorant of its power of injuring the foto-infantile mechanism of calcification, and while it seems possible that some cases of low virulence and latency escape our present methods. I find it, however, more rational to regard its action in that kind as nonspecific, and its association with craniotabes as having the same meaning as its association with rickets, which in the human subject is deceptively close, the action in both conditions being to promote resorption of bone. In other words, were it not for the presence of syphilis, many of these craniatrophies would not have time to reach a degree where they can be clinically recognised.

$\dagger$ All that is up to now determined is the agent, or one of the agents, preventimg rickets. The causes producing it come into play aftor the re unknown.

which have Prof. Beattie's permission to mention these results 
Regarding rickets, my observations suggest that it is clinically associated with much the same frequency as syphilis.' Though the severity of craniotabes and a subsequent rickets often varies directly, this ratio is quite inconstant. The feeding in 105 cases when first found with infantile craniotabes (extreme ages 1 and 9 months) was: exclusive

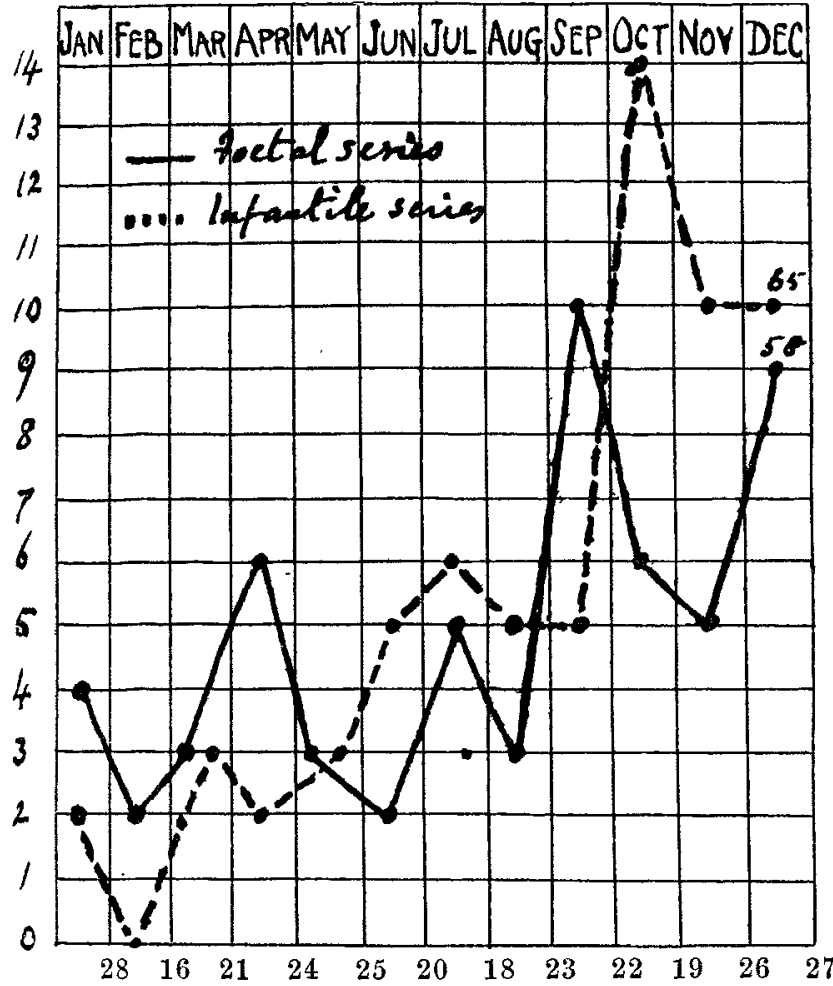

Frg, 5.-Chart showing the months of birth of 123 craniotabetics breast-feeding, 62; mixed feeding, 14; exclusive hand-feeding, 29. In the breast-fed the atrophies were not less extensive, but usually partial in degree. That so many were breast-fed is against expectation, but it may be argued that, ceteris paribus, if the maternal blood cannot prevent craniotabes the maternal milk will not be able to prevent it afterwards.

The point on which observation can best help theory appears to me that of seasonal incidence. This is now being worked out. The results so far are shown herewith, though their inadequacy as yet is patent. The month of birth is stated for 123 in which it is known. The infantile series includes cases only observed with that form. In the fotal cases (58) an error involved in such estimates can be checked by knowing the number of births per month among which they occurred (see foot of chart).

It seems, therefore, that a seasonal curve may exist. Thus 51 per cent. of the foetal series, and 60 per cent, of the infantile, were born in the last four months of the year. Supposing the bulk of foetal cases to show infantile recurrence, it would follow that infantile craniotabes will be chiefly met with, at any rate in its worst degrees, in the first few months of each year.

If a marked winter aggravation is confirmed by larger figures, it will serve to that extent to ally craniotabes with rachitic phenomena in general. But the chief difficulty remains. We have seen that the early disappearance of craniotabes is no obstacle to its acceptance as a true sign of rickets; but its early appearance constitutes a difficulty which has already existed for the earlier infantile examples, and is only somewhat increased by bringing in the last few weeks of pre-natal life. A partial solution may be attempted, however, by recognising the influence of stress on the individual bones in determining the order of rachitic bone changes in general. Such knowledge as we have indicates that the stresses on the fotal long bones are generally less intense than those obtaining in the outer world. But the stress on the dependent cranium must be considerable, both by its position in the relatively rigid lower uterine segment, and by the interior brain-mass for some 16 hours out of each 24 , the total stress being probably greater then than after birth. Add to these considerations the partial immunity of the foetus against adverse maternal influences, and the possibility, by analogy, that any such effects might be shown in a modified form at these early periods, and the difficulty becomes, perhaps, less formidable.

With this particular problem, however, observation can do little, and one awaits the results of the experimentalist, especially on such subjects as the effects on the foetus of ill-balanced maternal diets involving deprivation of vitamin $A$, and the causes of osteomalacia.

References. - 1. THE LANCET, June 13th, 1918. 2. Brit. Jour. Child. Dis., February, 1908. 3. Findlay, L., Med. Researeh Com., Special Report, No. 20, 19. 4. Ibid. 5. Pfaundler, M., and schlossmann, A., Dis. of Ch. 1912, vol. ii., art. Rachitis. 6. Still, G. F., Disorders of Childh., second edition, 73-1 , (1) 299. \&c.

\section{ANTIMONY AND EMETINE IN BILHARZIA DISEASE.}

BY F. G. CA WSTON, M.D. CAMB.

Is 1917 Dr. J. B. Christopherson established tartar emetic as the routine treatment for bilharzia disease in Egypt, and no equally effective but less toxic preparation of antimony is at present available. Undesirable results of unskilful administration of the drug are still being experienced in various parts of South Africa, the solution causing necrosis through being injected under the skin instead of into the blood stream. Sometimes large doses are given before the usual tolerance for the drug has been acquired, and occasionally the doses given are too small to produce any appreciable effect on the parasites.

During 1920 I recorded ${ }^{1}$ my results obtained by treating a number of cases of bilharzia disease by intravenous injections of a freshly prepared solution of tartar emetic, the injections being given on alternate days shortly after a light breakfast, the dose varying from $\frac{1}{4}$ gr. to $1 \frac{1}{2}$ gr. The doses were gradually increased until the largest dose that the patient could comfortably tolerate was reached. The subsequent history of these and other cases show that, where the injections are given regularly over a period of 28 days, there is little possibility of a return of the symptoms. A dose of more than two grains is unnecessary; larger doses do not appear to effect a cure any more rapidly. It is always risky to discontinue treatment before the 28th day or to give the injections less frequently than three times a week. I have seen recurrences when $15 \mathrm{gr}$. have been administered over a period of 24 days and others where four days have been missed in the middle of treatment, but none where treatment has been continued without interruption for 28 days, even though no greater total dose has been given.

The powder was dissolved in from 4 to $12 \mathrm{c.cm}$. of boiling distilled water just before being drawn up out of a wide-mouthed test-tube into an all-glass serum syringe which had already been sterilised and had a suitable needle attached. It has always been my practice to boil both needle and syringe before use, and to paint the skin with rectified spirit before injecting the needle, and I see no reason to alter this procedure. Without discolouring the skin, spirit rapidly produces a clot which helps to arrest bleeding and assists in rendering the seat of injection both aseptic and anæsthetic. Incompletely cured cases of bilharzia disease are especially liable to attacks of renal colic, and when the general health does not rapidly improve after treatment it is generally because all the parasites have not been destroyed. These attacks of colic which sometimes occur during the course of treatment are probably due to an accumulation of incompletely destroyed ova in the kidney substance, which, under ordinary circumstances, The LANCET 1920, ii., 392. 